\title{
SOIL WATER MANAGEMENT PROBLEM USING FUZZY ARITHMETIC
}

\author{
I.N. HALKIDIS ${ }^{1}$ \\ CH.D. TZIMOPOULOS ${ }^{1, *}$ \\ CH.H. EVANGELIDES ${ }^{1}$ \\ M. SAKELLARIOY- \\ MAKRANTONAKI ${ }^{2}$
}

Received: 23/05/08

Accepted: 13/10/08

\author{
${ }^{1}$ Department of Rural and Surveying Engineering \\ Aristotle University of Thessaloniki \\ 54124, Thessaloniki, Greece \\ ${ }^{2}$ Department of Agriculture, Crop Production and Rural \\ Environment, University of Thessaly \\ Fytokou Street, N. Ionia, GR-384 46, Volos, Greece
}

*to whom all correspondence should be addressed: e-mail: tzimop@vergina.eng.auth.gr

\begin{abstract}
Drainage management problems are usually very hard to simulate due to the uncertainty of the hydraulic parameters involved. Fuzzy analysis is one of the available tools that can be used for such problems, involving uncertain data. A fuzzy analysis approach usually involves the consideration of several $\alpha$-level cuts and an analytical approach or an explicit scheme approach for the PDE's discretization. Several application examples of this approach are listed in the literature, including uncertainty in hydraulic conductivity, specific yield, transmissivities, porosities, dispersivities, and deoxygenation rate coefficient.

A methodology for the simulation of drainage problem having vague values of hydraulic parameters is introduced in this paper, and an analytical solution for a two-dimensional drainage application is presented. The two-dimensional problem of drainage is handled using fuzzy analysis by defining the hydraulic conductivity $K$ as a triangular fuzzy number (TFN). The method of interval analysis is used in all the a-level cut examples. A solution is obtained using eleven $\alpha$-level cuts and also solutions for two, three, and five $\alpha$-level cuts are presented. Trials for different values of effective porosity are also performed. Finally conclusions on the necessary number of $\alpha$-cuts utilized for drainage problems are drawn.
\end{abstract}

KEYWORDS: Drainage management, fuzzy numbers, fuzzy arithmetic, uncertainty, hydraulic conductivity, effective porosity.

\section{INTRODUCTION}

Fuzziness, as handled in fuzzy logic, can refer to various types of vagueness and uncertainty but particularly to the vagueness related to human linguistics and thinking, differing from the uncertainty of the Probabilistic Theory (Tanaka, 1991).

It is well known from the scientific society that simulation of natural phenomena involves parameters which cannot be measured accurately and their approximate value is used. This vagueness of the parameters affects all the mathematical models that are used. Example of vague parameters in ground water systems is the parameters of aquifer or the dispersion coefficient or the saturated water content.

This vagueness of the parameters has a great influence on the arithmetic results and should be taken into account during calculations. Fuzzy logic theory which was developed by Zadeh (1965) is one way of dealing with this uncertainty.

This theory although was accepted with a lot of cautiousness from the scientific society it was rapidly evolved from Sugeno (1972) who applied it in uncertainty measurements and uncertainty intervals and Mamdani from University of London (Mamdani, 1974) and his associates who used fuzzy logic in control systems and more specifically to control the temperature in a rotary cement kiln. Fuzzy logic models today, have widespread applications 
in decision making, in control theory, in predicting and optimizing, since they can transform vague linguistic information into arithmetic form. Fuzzy models do not replace traditional models by any means, instead they provide a quick and simple method of calculation, in cases where exact data is unreliable and calculations are complicated. Finally fuzzy logic approaches with a more scientific and logical way the description of the properties of an item.

In hydraulic engineering Dou et al. (1995) examined an aquifer under pressure and steady state condition with vague hydraulic parameters and they solved the resulting arithmetic scheme with intervals. Chang et al. (1996) presented a theoretical method of programming with many objective functions where messages were fuzzy. Dou et al. (1997a) presented a transient model of an aquifer under pressure with vague parameters and compared the results of the arithmetic model with the analytical solution of Theis. Dou et al. (1997b) presented a fuzzy logic model in dispersion problems. Teegavarapu and Simonovich (1999) performed modelling of the uncertainty in the reservoir loss functions using fuzzy sets. Mujumdar and Sasikumar (2002) presented a fuzzy optimization model for the seasonal water quality management of river systems. The model addresses the uncertainty in a water quality system in a fuzzy probability framework. The occurrence of low water quality is treated as a fuzzy event. Randomness associated with the water quality indicator is linked to this fuzzy event using the concept of probability of a fuzzy event. Faye et al. (2003) presented a fuzzy logic model for long-term storage/transfer/distribution of water management system.

One other class of problems involves systems of fuzzy rules which have applications in: reservoir management where Shrestha et al. (1996) worked on a multipurpose reservoir system, hydrology problems where Piechota and Dracup (1996) used 94 years of monthly Palmer Drought Severity Index (PDSI) data and their article investigates the hydroclimatic response in the United States to the extreme phases of the Southern Oscillation (EI Niño and La Nina). Dou et al. (1999) developed a fuzzy rule-based model for solute transport in the unsaturated zone. Their change from using fuzzy numbers to represent imprecise variables in traditional finite difference solutions to models entirely based on fuzzy rules has mirrored the similar development of surface flow models.

Ganoulis (1994) presented risk analysis in environmental problems. Mpimpas et al. (1998) presented the one dimensional solution of polluting element dispersion in a river. The fuzzy variables utilized, were the dispersion coefficient and the two decomposition coefficients. Mpimpas (1998) worked on arithmetic investigation of polluting elements dispersion using fuzzy logic, Ganoulis (2000) solved an aquifer recharge problem with infiltration where the diffusion coefficient was not precisely known. Chalkidis (2005) and Chalkidis et al. (2006) worked on aquifer management problems using fuzzy logic and fuzzy linear programming. Mpallas (2007) worked on management and hydrological problems using fuzzy rules, and Tzimopoulos et al. (2004) worked on two dimensional unsteady flow using fuzzy logic. Tzimopoulos et al. (2005) presented a quasi similar and shortened version of this paper, using fuzzy logic.

In this article the case of a drainage management problem in unconfined aquifer is presented in which the hydraulic parameters experience uncertainty. Emphasis is given on water level during drainage for different confidence intervals $\alpha$ and the membership functions are presented for different drainage times. Finally the real values are presented after defuziffication.

\section{PRELIMINARIES}

\section{Definition 1. Fuzzy set.}

If $X$ is a collection of objects denoted generically by $x$, then a fuzzy set $A$ in $X$ is a set of ordered pairs: $A=\left\{\left(x, \mu_{A}(x)\right) \mid x \in X\right\}$. Where $\mu_{A}(x)$ is the membership function or grade of membership of $x$ in $A$ that maps $X$ to the membership space.

The support (domain) of a fuzzy set $A$ is the crisp set of elements $x$ such that $\mu_{A}(x)>0$. The range of the membership function is a subset of the nonnegative real numbers whose supremum is finite. 


\section{Definition 2. Convex fuzzy set.}

A fuzzy set is considered convex when its objective function increases and then decreases monotonically and there is no local minimum. A fuzzy set is convex if:

$\mu_{\mathrm{A}}\left(\lambda \mathrm{x}_{1}+(1-\lambda) \mathrm{x}_{2}\right) \geq \min \left\{\mu_{\mathrm{A}}\left(\mathrm{x}_{1}\right), \mu_{\mathrm{A}}\left(\mathrm{x}_{2}\right)\right\}, \quad \forall \mathrm{x}_{1}, \quad \mathrm{x}_{2} \in \mathrm{X}, \lambda \in[0,1]$

Definition 3. $\alpha$-level cut.

The set of elements belonging to the fuzzy set $A$ at least to the degree $\alpha$ is called the $\alpha$-level cut .

$$
\mathrm{A}_{\alpha}=\left\{\mathrm{x} \mid \mu_{\mathrm{A}}(\mathrm{x}) \geq \alpha\right\}, \quad \alpha \in[0,1] \text {. If } \mathrm{A}_{\alpha}^{\prime}=\left\{\mathrm{x} \mid \mu_{\mathrm{A}}(\mathrm{x})>\alpha\right\} \text {, then it is called "strong } \alpha \text {-level cut". }
$$

\section{Definition 4. Fuzzy numbers.}

A fuzzy number $\mathrm{M}$ is a convex normalized set $\mathrm{M}$ of the real line $R$ such that:

1. It exists at least one $x_{0} \in R$ with $\mu_{\mathrm{M}}\left(\mathrm{x}_{0}\right)=1$

2. $\mu_{M}(x)=1$ is piecewise continuous.

When fuzzy set theory is used to solve real problems of realistic size, it is more efficient to use a special type of fuzzy numbers, the LR-type (Zimmermann, 1996).

\section{Definition 5. LR-type.}

A fuzzy number $M$ is of LR-type if there exist reference functions $L$ (for left), $R$ (for right), and scalars $\alpha>0, \beta>0$ with

$$
\mu_{M}(x)=\left\{\begin{array}{lll}
L\left(\frac{m-x}{\alpha}\right) & \text { For } \quad x \leq m \\
R\left(\frac{x-m}{\beta}\right) & \text { For } x \geq m
\end{array}\right.
$$

$m$, is a real number called the mean value of $M$, and $\alpha$ and $\beta$ are called the left and right spreads respectively. A triangular fuzzy number (TFN) is a special case of semisymmetric LR fuzzy number (Kaufmann and Gupta, 1991; Zimmermann, 1996). To specify a TFN we use the three values $\left(\alpha_{1}, \alpha_{2}, \alpha_{3}\right)$ of the triangle base, where $\alpha_{1} \leq \alpha_{2} \leq \alpha_{3}$.

\section{Interval Analysis}

Strictly speaking, these special cases of fuzzy numbers are fuzzy intervals. So every a-level cut, actually, gives an interval number. Disposing various a-level cuts we can construct a fuzzy number in discrete form. Finally, if we want to use fuzzy sets in applications, we will have to deal with interval number operations (Moore, 1966; Dou et.al., 1995; Zimmermann, 1996).

If ${ }^{*}$ is one of the symbols $+,-, \cdot, /$, we define arithmetic basic operations on interval number by $[a, b] *[c, d]=\{x * y \mid a \leq x \leq b, c \leq y \leq d\}$ except that we do not define $[a, b] /[c, d]$ if $0 \in[c, d]$.

Specifically,

$[a, b]+[c, d]=[a+c, b+d]$

$[a, b]-[c, d]=[a-d, b-c]$

$[a, b] \cdot[c, d]=[\min (a c, a d, b c, d b), \max (a c, a d, b c, d b)]$

$[a, b] /[c, d]=[a, b] \cdot[1 / d, 1 / c] \quad$ if $0 \notin[c, d]$.

\section{PROBLEM FORMULATION}

In this article, a two-dimensional analytical solution for obtaining the groundwater level is presented. Examples of real applications are: Drainage of an area by drainpipes or natural ground configurations or drainage systems with subsequent well points, which are applied in soil operations in dry conditions, on grounds with a rich groundwater supply.

The analytical solution of the two-dimensional problem is derived from the two-dimensional linearized Boussinesq equation.

$$
\frac{\partial \mathrm{H}}{\partial \mathrm{t}}=\alpha\left\{\frac{\partial^{2} \mathrm{H}}{\partial \mathrm{x}^{2}}+\frac{\partial^{2} \mathrm{H}}{\partial \mathrm{y}^{2}}\right\} \text {, }
$$


where $\alpha=\mathrm{K} \overline{\mathrm{H}} / \mathrm{S}$, $\mathrm{t}$ denotes time, $\mathrm{x}$, y Cartesian coordinates, $\mathrm{H}$ water table elevation, $\mathrm{K}$ the hydraulic conductivity, $\bar{H}$ the average value of the water table elevation and $\mathrm{S}$ is the effective porosity of the soil. The initial and boundary conditions are (Figures 1 and 2):

$$
\begin{array}{ll}
t=0, & H(x, y, 0) \quad=H_{1} \\
x= \pm R_{x}, & H\left( \pm R_{x}, y, t\right)=H_{a} . \\
y= \pm R_{y}, & H\left(y, \pm R_{y}, t\right)=H_{a}
\end{array}
$$

For one-dimensional problem the analytical solution is as follows: (Tzimopoulos, 1983; Chalkidis, 2005).

$$
\begin{aligned}
& \frac{H(x, t)-H_{a}}{H_{1}-H_{a}}=\sum_{n=1}^{\infty} \frac{2}{k_{n}}(-1)^{n+1} \cos \left(k_{n} \frac{2 x}{R_{x}}\right) e^{-k_{n}^{2} \frac{a t}{R_{x}^{2}}}=\frac{4}{\pi} \sum_{n=1}^{\infty} \frac{(-1)^{n+1}}{(2 n-1)} \cos \frac{(2 n-1) \pi x}{R_{x}} e^{-k_{n}^{2} \frac{\text { at }}{R_{x}^{2}}} \\
& \left(k_{n}=(2 n-1) \frac{\pi}{2}\right)
\end{aligned}
$$

where $t$ denotes time, $x$ denotes distance from the drainpipe and $R_{x}$ is the half of the drain spacing.

Utilizing the above solution and extending it, for the two-dimensional drainage problem the following solution is obtained. (Tzimopoulos, 2004; Chalkidis, 2005).

$$
\begin{aligned}
& \frac{\mathrm{H}(\mathrm{x}, \mathrm{y}, \mathrm{t})-\mathrm{H}_{\mathrm{a}}}{\mathrm{H}_{1}-\mathrm{H}_{\mathrm{a}}}=\left(\frac{4}{\pi}\right)^{2} \sum_{\mathrm{n}=0}^{\infty} \sum_{\mathrm{m}=0}^{\infty} \frac{(-1)^{\mathrm{n}}}{(2 \mathrm{n}+1)} \frac{(-1)^{\mathrm{m}}}{(2 \mathrm{~m}+1)} \cos \mathrm{N}_{\mathrm{x}} \cos \mathrm{M}_{\mathrm{y}} \mathrm{e}^{-\mathrm{w}} \\
& \mathrm{N}_{\mathrm{x}}=\frac{(2 \mathrm{n}+1) \pi \mathrm{x}}{2 \mathrm{R}_{\mathrm{x}}}, \quad \mathrm{M}_{\mathrm{y}}=\frac{(2 \mathrm{~m}+1) \pi \mathrm{y}}{2 \mathrm{R}_{\mathrm{y}}}, \mathrm{w}=\mathrm{at}\left\{\frac{\mathrm{k}_{\mathrm{n}}^{2}}{\mathrm{R}_{\mathrm{x}}^{2}}+\frac{\mathrm{k}_{\mathrm{m}}^{2}}{\mathrm{R}_{\mathrm{y}}^{2}}\right\}
\end{aligned}
$$

\section{PROBLEM SOLUTION}

Solution (3) is applied to a subsurface drainage problem for a homogeneous and isotropic soil. A rectangular area with a pipe drainage system is assumed (Figure 1). The drainpipes are located at the four sides of the rectangular and a Cartesian axes system is referenced to the centre of the rectangular area.

The initial condition is the saturated status of the area and at time $t=0$ the ground water starts to drain to the surrounding drainpipes. The phenomenon is symmetric; therefore the theoretical solution can be applied just to the quarter of the study area.

Initial conditions: $\quad \mathrm{t}=0 \mathrm{~d}, \mathrm{H}(\mathrm{x}, \mathrm{y}, 0)=\mathrm{H}_{1}=3 \mathrm{~m}$

Boundary conditions: $x=R_{x}=100 m, H(100, y, t)=H_{a}=1 m, y=R_{y}=100 m, H(x, 100, t)=H_{a}=1 m$

In the specific drainage management problem the exact value for hydraulic conductivity is not known. A range of values is assigned based on previous experience for agricultural land and a solution is established for the specific drainage problem, based on the fact that hydraulic conductivity is a fuzzy number.

When calculations include at least a fuzzy number, then the solution becomes a fuzzy number also (Dou et al., 1995). Consequently, for every time step and every spatial step, the water depth, which is a fuzzy number, is found.

Assuming that in the area under consideration a series of measurements of hydraulic conductivity was carried out, giving as minimum value of conductivity $6 \mathrm{~m} \mathrm{~d}^{-1}$ corresponding to a Silt loam soil, a dominant value of $15 \mathrm{~m} \mathrm{~d}^{-1}$, corresponding to a Sandy Loam soil and a maximum value of $22 \mathrm{~m} \mathrm{~d}^{-1}$, corresponding to a Loamy Sand soil (Dieleman and Trafford, 1976), the corresponding representation of hydraulic conductivity as a fuzzy number is shown on Figure 3. 


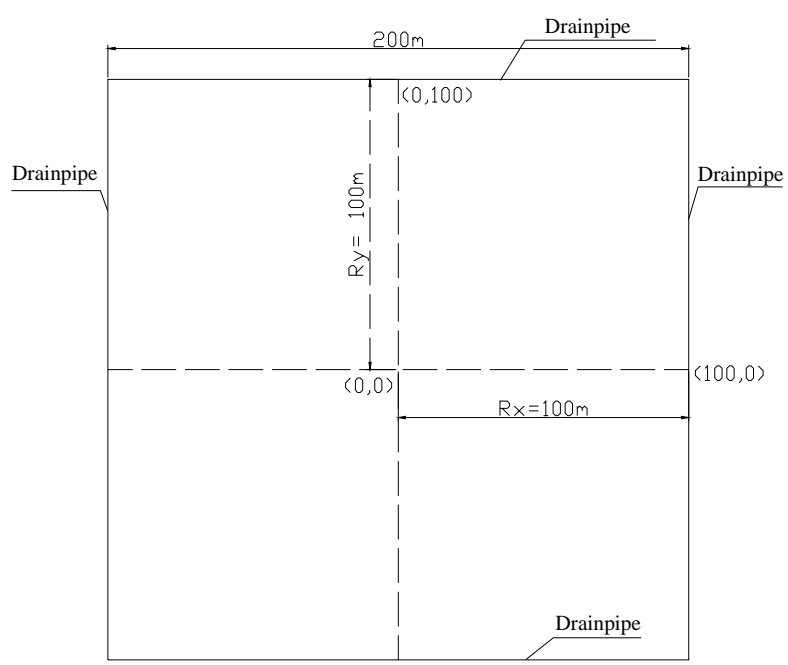

Figure 1. Area with a pipe drainage system Solution (3) gives the temporal and spatial value of the water table height in every position given by the combination of the position $\mathrm{x}, \mathrm{y}$ in every time $\mathrm{t}$

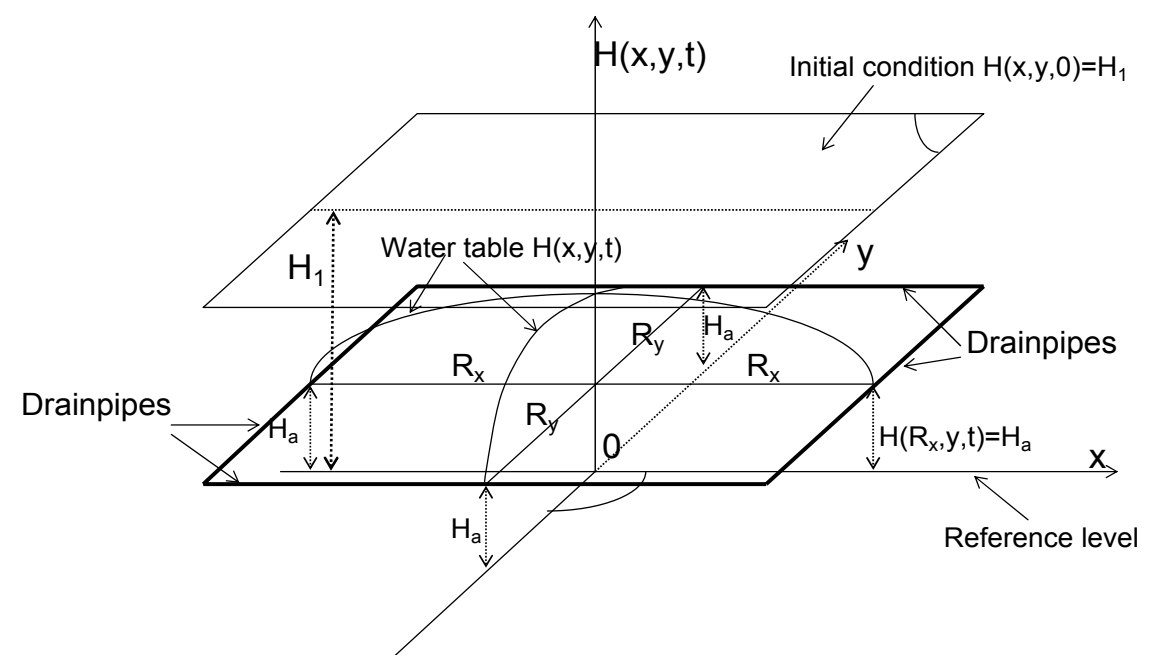

Figure 2. Drainage system

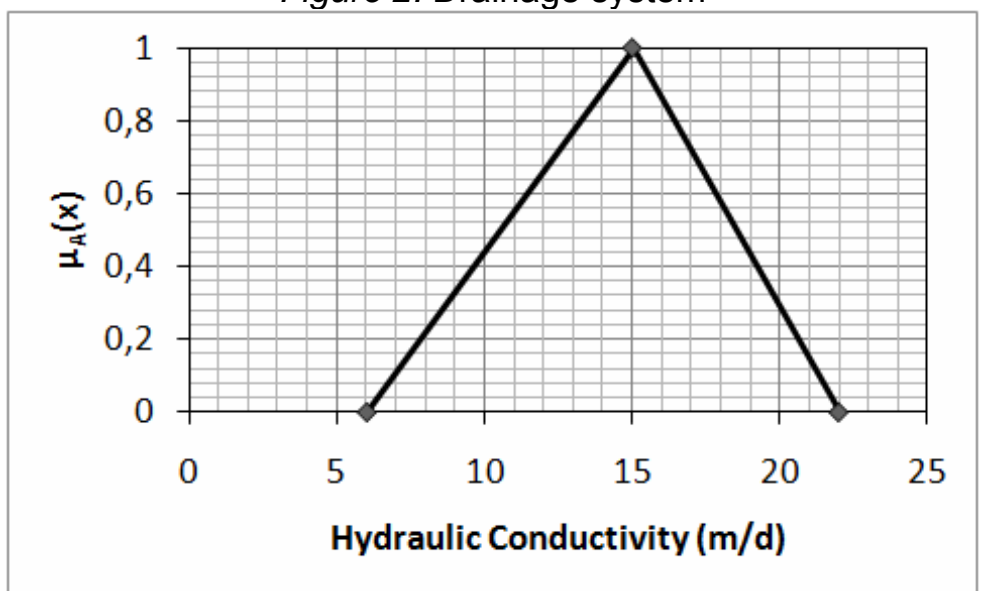

Figure 3. Fuzzy number of hydraulic conductivity

In order to introduce the fuzzy number in the equation, the method of interval analysis is utilized (Moore, 1966) and different results are compared for 2, $\left(\mu_{\mathrm{A}}=0,1\right), 3,\left(\mu_{\mathrm{A}}=0,0.5,1\right)$, $5,\left(\mu_{\mathrm{A}}=0,0.25,0.5,0.75,1\right)$, and $11,\left(\mu_{\mathrm{A}}=0,0.1,0.2,0.3 \ldots \ldots .1\right) \alpha$-level cuts in order to examine the sensitivity of the result on the number of $\alpha$-level cuts. 
The same procedure is also repeated for different values of the effective porosity in order to examine the variations of the results as a function of the effective porosity.

Every solution was carried out for three values of the effective porosity $S_{1}=0.001, S_{2}=0.01$ and $S_{3}=0.1$ at the point $x=y=0$ and for different drainage times.

For the defuzzification we used the method of fuzzy mean, or centre of gravity (COG), the value $x$ of centre of gravity being the crisp value of water table. Thus the comparison of the results ends up being the comparison of the $x$ values of the centers of gravity.

The centre of gravity of the complex forms is calculated by first calculating the centre of gravity of each of the trapeziums and of the triangle which are generated from the a-cuts. Finally the resultant coordinates are calculated. The results concerning the variation of the water level during drainage are shown on Table 1 and solutions with membership function $\mu(x)=1$ are also given.

Table 1. Defuzzified values for $11,5,3$ and $2 \alpha$-level cuts and effective porosity of $S=0.001,0.01 \mathrm{kal} 0.1$ at $\mathrm{x}=\mathrm{y}=0$ at different drainage times

\begin{tabular}{|c|c|c|c|c|c|c|c|c|c|}
\hline \multirow{3}{*}{$t(d)$} & & \multirow{2}{*}{\multicolumn{5}{|c|}{$S_{2}=0.01$}} \\
\hline & & & & & & & & & \\
\hline & G 11 & & \multirow{2}{*}{$\frac{G 3}{3.00}$} & \multirow{2}{*}{$\frac{G 2}{3.00}$} & \multirow{2}{*}{\begin{tabular}{r|} 
G 11 \\
3.00 \\
\end{tabular}} & \multirow{2}{*}{\begin{tabular}{c|} 
G 5 \\
3.00 \\
\end{tabular}} & \multicolumn{2}{|c|}{ G 3} & \multirow{2}{*}{$\begin{array}{l}\mathrm{G} 2 \\
3.00\end{array}$} \\
\hline 0 & 3.00 & 3.00 & & & & & 3. & 00 & \\
\hline 0,1 & 1.04 & 1.05 & 1.06 & 1.10 & 2.68 & 2.68 & 2. & 68 & 2.66 \\
\hline 0,2 & 1.00 & 1.00 & 1.00 & 1.01 & 2.08 & 2.08 & $2.0 s$ & & 2.12 \\
\hline 0,3 & 1.00 & 1.00 & 1.00 & 1.00 & 1.68 & 1.69 & 1. & 71 & 1.77 \\
\hline 1 & 1.00 & 1.00 & 1.00 & 1.00 & 1.04 & 1.05 & 1. & 06 & 1.10 \\
\hline 2 & 1.00 & 1.00 & 1.00 & 1.00 & 1.00 & 1.00 & 1. & 00 & 1.01 \\
\hline 3 & 1.00 & 1.00 & 1.00 & 1.00 & 1.00 & 1.00 & 1. & 00 & 1.00 \\
\hline 5 & 1.00 & 1.00 & 1.00 & 1.00 & 1.00 & 1.00 & 1. & 00 & 1.00 \\
\hline 10 & 1.00 & 1.00 & 1.00 & 1.00 & 1.00 & 1.00 & 1. & 00 & 1.00 \\
\hline \multirow[t]{3}{*}{20} & 1.00 & 1.00 & 1.00 & 1.00 & 1.00 & 1.00 & 1. & 00 & 1.00 \\
\hline & \multicolumn{4}{|c|}{$S_{3}=0.1$} & \multicolumn{5}{|c|}{$\mu(x)=1$} \\
\hline & G 11 & G 5 & G 3 & G 2 & $S_{1}=0.001$ & $S_{2}=0$. & & $\mathrm{S}_{3}=$ & \\
\hline 0 & 3.00 & 3.00 & 3.00 & 3.00 & 3.0 & & 3.00 & & 3.00 \\
\hline 0,1 & 3.00 & 3.00 & 3.00 & 3.00 & 1.0 & & 2.68 & & 3.00 \\
\hline 0,2 & 2.99 & 2.99 & 2.99 & 2.99 & 1.0 & & 1.98 & & 2.99 \\
\hline 0,3 & 2.99 & 2.99 & 2.99 & 2.99 & 1.0 & & 1.54 & & 2.99 \\
\hline 1 & 2.68 & 2.68 & 2.68 & 2.66 & 1.0 & & 1.01 & & 2.68 \\
\hline 2 & 2.08 & 2.08 & 2.09 & 2.12 & 1.0 & & 1.00 & & 1.98 \\
\hline 3 & 1.67 & 1.68 & 1.70 & 1.77 & 1.0 & & 1.00 & & 1.54 \\
\hline 5 & 1.28 & 1.29 & 1.32 & 1.39 & 1.0 & & 1.00 & & 1.16 \\
\hline 10 & 1.04 & 1.05 & 1.06 & 1.10 & 1.0 & & 1.00 & & 1.01 \\
\hline 20 & 1.00 & 1.00 & 1.00 & 1.01 & 1.0 & & 1.00 & & 1.00 \\
\hline
\end{tabular}

Figure 4 shows fuzzy values using the solution (3) with $2,\left(\mu_{A}=0, \mu_{A}=1\right), 5\left(\mu_{A}=0, \mu_{A}=0.25\right.$ $\left.\mu_{\mathrm{A}}=0.5, \mu_{\mathrm{A}}=0.75, \mu_{\mathrm{A}}=0.1\right)$ and $11\left(\mu_{\mathrm{A}}=0, \mu_{\mathrm{A}}=0.1, \mu_{\mathrm{A}}=0.2, \mu_{\mathrm{A}}=0.3 \ldots . . \mu_{\mathrm{A}}=1\right) \alpha$-cuts at point $(0,0)$ for time $t=1 \mathrm{~d}$ and for $S_{2}=0.01$. Figure 5 shows fuzzy values with $2,3\left(\mu_{\mathrm{A}}=0, \mu_{\mathrm{A}}=\right.$ $\left.0.5, \mu_{A}=1\right)$ and $11 \alpha$-cuts at point $(0,0)$ for time $t=1 d$ and for $S_{2}=0.01$.

At the Figures 4 and 5 "G025" is the gravity centre of the trapezium between the intervals at $\alpha$-cut 0 and $\alpha$-cut 0.25 . Respectively "G050" is the gravity centre of the trapezium between the intervals at $\alpha$-cut 0.25 and $\alpha$-cut 0.50 , "G075" is the gravity centre of the trapezium between 
the intervals at $\alpha$-cut 0.50 and $\alpha$-cut 0.75 and " $G 1$ " is the gravity centre of the triangle between the intervals at $\alpha$-cut 0.75 and $\alpha$-cut 1 . Also at the Figures 4 and 5 " $G 2 \alpha$-cut" is the gravity centre of the TFN, "G 3 a-cut", "G 5 a-cut", "G 11 a-cut", are the gravity centre of the of the 3, 5 and 11 a-cut shape solutions respectively.

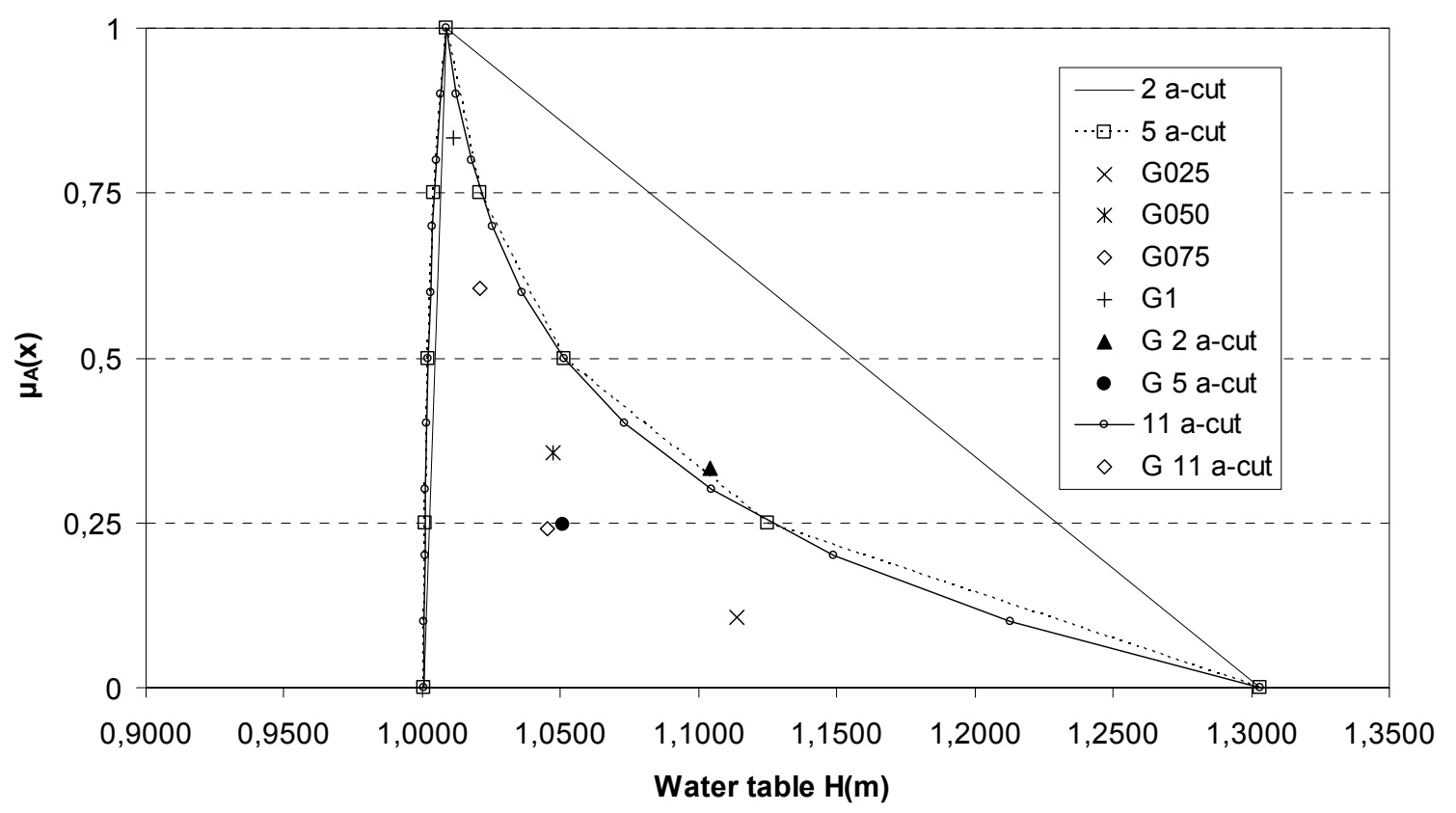

Figure 4. Fuzzy value of water table level $\mathrm{H}$ at position $(0,0)$ after 1-day drainage with $\mathrm{S}_{2}=0.01$ for 11,5 and $2 \alpha$-level cuts

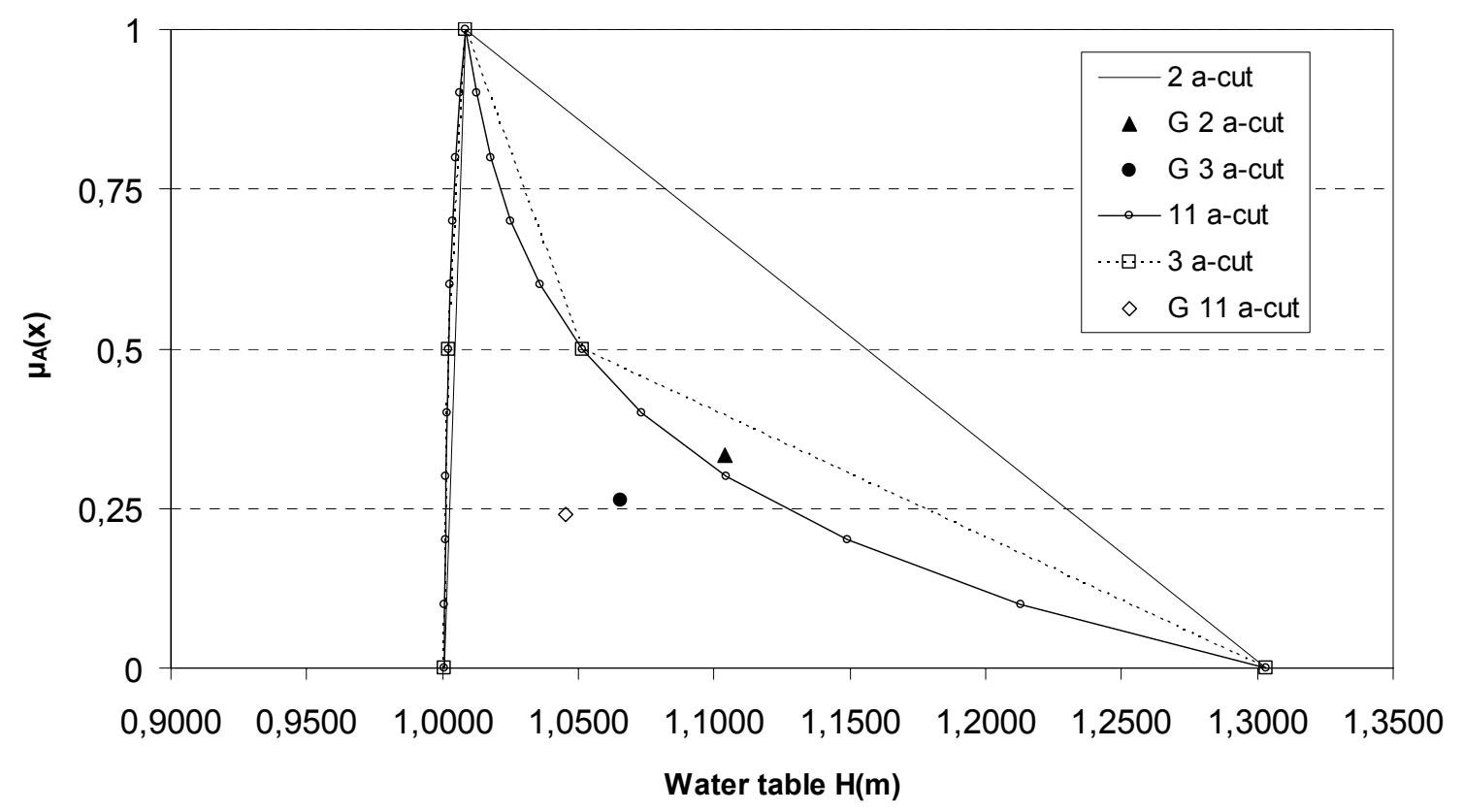

Figure 5. Fuzzy value of water table level $\mathrm{H}$ at position $(0,0)$ after 1-day drainage with $S_{2}=0.01$ for 11,3 and 2 -level cuts

The relative mean square error (rmse) is used in order to compare the defuzzified values of the four fuzzy solutions and the results are shown on Table 2. 
Table 2. The relative mean square error (rmse) of 5, 3 and 2 a-level cuts in respect to $11 \alpha$-level cuts

\begin{tabular}{|c|c|c|c|c|c|c|}
\hline & \multicolumn{3}{|c|}{$S_{1}=0.001$} & \multicolumn{3}{|c|}{$S_{2}=0.01$} \\
\hline$t(d)$ & $\begin{array}{c}\text { rmse } \\
(\mathrm{G} 11, \mathrm{G} 5)\end{array}$ & $\begin{array}{c}\text { rmse } \\
(\mathrm{G} 11, \mathrm{G} 3)\end{array}$ & $\begin{array}{c}\text { rmse } \\
(\mathrm{G} 11, \mathrm{G} 2)\end{array}$ & $\begin{array}{c}\text { rmse } \\
(\mathrm{G} 11, \mathrm{G} 5)\end{array}$ & $\begin{array}{c}\text { rmse } \\
(\mathrm{G} 11, \mathrm{G} 3)\end{array}$ & $\begin{array}{c}\text { rmse } \\
(\mathrm{G} 11, \mathrm{G} 2)\end{array}$ \\
\hline 0 & 0,00000 & 0,00000 & 0,00000 & 0,00000 & 0,00000 & 0,00000 \\
\hline 0,1 & 0,00275 & 0,03534 & 0,28494 & 0,00001 & 0,00028 & 0,00485 \\
\hline 0,2 & 0,00006 & 0,00073 & 0,00515 & 0,00074 & 0,00592 & 0,04830 \\
\hline 0,3 & 0,00000 & 0,00001 & 0,00005 & 0,00339 & 0,03369 & 0,29176 \\
\hline 1 & 0,00000 & 0,00000 & 0,00000 & 0,00275 & 0,03534 & 0,28494 \\
\hline 2 & 0,00000 & 0,00000 & 0,00000 & 0,00006 & 0,00073 & 0,00515 \\
\hline 3 & 0,00000 & 0,00000 & 0,00000 & 0,00000 & 0,00001 & 0,00005 \\
\hline 5 & 0,00000 & 0,00000 & 0,00000 & 0,00000 & 0,00000 & 0,00000 \\
\hline 10 & 0,00000 & 0,00000 & 0,00000 & 0,00000 & 0,00000 & 0,00000 \\
\hline \multirow[t]{2}{*}{20} & 0,00000 & 0,00000 & 0,00000 & 0,00000 & 0,00000 & 0,00000 \\
\hline & \multicolumn{3}{|c|}{$S_{3}=0.1$} & & & \\
\hline$t(d)$ & $\begin{array}{c}\text { rmse } \\
(\mathrm{G} 11, \mathrm{G} 5)\end{array}$ & $\begin{array}{c}\text { rmse } \\
(\mathrm{G} 11, \mathrm{G} 3)\end{array}$ & $\begin{array}{c}\text { rmse } \\
(\mathrm{G} 11, \mathrm{G} 2)\end{array}$ & & & \\
\hline 0 & 0,00000 & 0,00000 & 0,00000 & & & \\
\hline 0,1 & 0,00000 & 0,00000 & 0,00000 & & & \\
\hline 0,2 & 0,00000 & 0,00000 & 0,00000 & & & \\
\hline 0,3 & 0,00000 & 0,00001 & 0,00005 & & & \\
\hline 1 & 0,00001 & 0,00028 & 0,00485 & & & \\
\hline 2 & 0,00074 & 0,00592 & 0,04830 & & & \\
\hline 3 & 0,00339 & 0,03369 & 0,29176 & & & \\
\hline 5 & 0,00719 & 0,08148 & 0,67787 & & & \\
\hline 10 & 0,00275 & 0,03534 & 0,28494 & & & \\
\hline 20 & 0,00006 & 0,00073 & 0,00515 & & & \\
\hline
\end{tabular}

\section{CONCLUSIONS}

The analytical solution for two-dimensional drainage problem was used for the investigation of the uncertainty of the drainage hydraulic conductivity $\mathrm{K}$ and effective porosity on the numerical results, utilizing a method of $11,2,3$ and 5 a-level cuts, using interval analysis (Moore,1966). With this analytical solution, the direct solution of the problem concerning the two-dimensional groundwater flow was achieved, without iterative calculations, for every point and at any time.

The results are compared with the results of $11 \alpha$-level cuts. The solutions are also carried out for different values of effective porosity $S_{1}=0.001 S_{2}=0.01$ and $S_{3}=0.1$. Table 2 shows the relative mean square error (rmse) of all the solutions and differences higher than 0.05 from the 11 a-level cut solution are pointed out. Useful information can be derived on the necessary number of $\alpha$-level cuts required in drainage problems

The results that are shown at Table 2 indicate that the solutions are practically the same for drainage with effective porosity $S$ equal to 0.001 and 0.01 when 11,5 or $3 \alpha$-level cuts are used. Differences are higher when 2 a-level cuts are used for certain times for all the values used for effective porosity $S$. These differences are shown with bold characters and concern the cases of $S_{1}=0.001$ and $t=0.1 d, S_{2}=0.01$ and $t=0.3$ and $1 d$ and $t=3,5$ and $10 d$. Differences are also found when $3 \alpha$-level cut is used when $S_{3}=0.1 \mathrm{ad} t=5 \mathrm{~d}$. 
In brief we can say that for effective porosities of $S_{1}=0.001$ and $S_{2}=0.01$ the use of at least 3 $\alpha$-level cuts is mandatory for accurate results, while for an effective porosity of $S_{2}=0.1$ is necessary to use 5 a-level cuts.

From Table 1 and Figures 4 and 5 it is obvious that the defuzzified solution for 11 a-level cuts is always closer to the value for which we accepted a membership function equal to $(\mu(x)=1)$ from the defuzzified solutions of 2,3 and 5 a-level cuts. The restrictions of the iterative calculations, truncations errors or logic errors, are removed by the analytical solution which permit simpler solution techniques.

\section{REFERENCES:}

- Ang A.H. and Tang W.H. (1984) Probability Concepts in Engineering Planning and Design, Vol.2, J. Wiley, New York.

- Dou C., Woldt W., Bogardi I. and Dahab M. (1995) Steady state groundwater flow simulation with imprecise parameters, Water Res. Res., 31(11), 2709-2719.

- Dou C., Woldt W., Dahab M. and Bogardi I. (1997a) Transient Ground-Water Flow Simulation Using a Fuzzy Set Approach, Groundwater, 35(2), 205-215.

- Dou C., Woldt, W., Bogardi I. and Dahab M. (1997b) Numerical Solute Transport simulation using fuzzy set approach, Journal of Contaminant Hydrology, 27(11), 107-126.

- Dou C., Woldt W. and Bogardi I. (1999) Fuzzy rule-based approach to describe solute transport in the unsaturated zone, J. Hydrol., 220, 74-85.

- Chalkidis I.N. (2005) Water Resources Management - Application of the Fuzzy logic theory in an aquifer, PhD Thesis, Department of Rural and Surveying Engineering, Aristotle University of Thessaloniki.

- Chalkidis I.N., Tzimopoulos Ch.D., Evangelides Ch.H. and Yannopoulos St. (2006) Application of Linear and Fuzzy Programming for Water Management of an Aquifer, WSEAS Transactions on Systems, 12(5), 2844-2849.

- Chang Ni-Bin, Wen C.G., Chen Y.L. and Yong Y.C. (1996) A grey fuzzy multiobjective programming approach for the optimal planning of a reservoir watershed, Part $A$, Theoretical development, Wat. Res., 30(10), 2320-2334.

- Dieleman P.J. and Trafford B.D. (1976) Drainage testing, FAO irrigation and drainage, Paper No 28. Rome Italy.

- Faye R.M., Sawadogo S., Lishou C. and Mora-Camino F. (2003) Long-term fuzzy management of water resource systems, Applied Mathematics and Computation, 137, 459475.

- Ganoulis J. (1994) Engineering risk Analysis of Water Pollution: Probabilities and Fuzzy Sets. Wiley.

- Ganoulis J. (2000) Reliability in groundwater recharge estimation using Fuzzy Arithmetic, In: Honorary Volume Dedicated to Professor Emeritus loannis D. Mittas, M. Konstantinidou, K. Serafimidis and Tsagas G. (Eds.), Thessaloniki, 159-170.

- Kaufmann A. and Gupta M.M. (1991) Introduction to fuzzy arithmetic: theory and applications, Van Nostrand Reinhold, New York.

- Mamdani M., (1974), Applications of fuzzy algorithms for control of a simple dynamic plant, Proceedings of IEE, 121(12), 1585-1588.

- Moore R., (1966), Interval Analysis. Prentice Hall.

- Mpallas L. (2007) Use of fuzzy rules in water resources management - Application in hydrological basin of Volvi lake., PhD Thesis, Department of Rural and Surveying Engineering, Aristotle University of Thessaloniki.

- Mpimpas H. (1988) Arithmetic investigation of polluting element dispersion using fuzzy logic PhD Thesis, Department of Civil Engineering, Aristotle University of Thessaloniki.

- Mpimpas H., Anagnostopoulos P. and Ganoulis J. (1998) Solution of the advection-diffusion equation combined with fuzzy arithmetic, In: Proceedings of Protection and restoration of the environment IV Conference, Sani, Chalkidiki, 249-256.

- Mujumdar P.P. and Sasikumar K. (2002) A fuzzy risk approach for seasonal water quality management of a river system, Water Res. Res., 38(1), 5.1- 5.9.

- Piechota T. and Dracup J. (1996) Drought and regional hydrologic variation in the United States: Associations with the El Niňo-Southern Oscillation, Wat. Res. Res., 32(5), 1359-1373. 
- Shrestha B., Duckstein L. and Stakhiv E. (1996) Fuzzy rule-based modelling of reservoir operation, J. Water Resour. Plann. Manag., 122(4), 262-269.

- Sugeno M. (1972) Fuzzy measures and fuzzy integrals, Trans. SICE 8(2).

- Tanaka K. (1991) An Introduction to Fuzzy Logic for Practical Applications, Springer.

- Teegavarapu R.S.V. and Simonovic S.P. (1999) Modeling uncertainty in reservoir loss functions using fuzzy sets, Water Res. Res., 35(9), 2815-2823.

- Tzimopoulos C., Chalkidis I., Moutsopoulos K., Yannopoulos S., Sakellariou M. and Evangelidis C. (2004) Fuzzy simulation of soil Water Balance for the case of two dimensional unsteady flow. Proc. EWRA Symposium on Water Resources Management, Volume III, Septemper 2-4, Izmir, Turkey, 1017-1026.

- Tzimopoulos Ch.D., Chalkidis I.N., Moutsopoulos K.N., Sakellariou M., Yannopoulos St. and Evangelides Ch.H. (2005) Soil Water Balance Using Fuzzy Calculation. Proc. $9^{\text {th }}$ Conference of CEST, Rhodos, Greece, (Ext. Abstract) pp. 430.

- Tzimopoulos Ch. (1983) Drainage - Phreatic hydraulics, Ziti Publisher (in Greek).

- Tzimopoulos Ch. (2004) Advanced drainage course, Course notes Aristotle University of Thessaloniki (in Greek).

- Zadeh L. (1965) Fuzzy sets, Information and Control, 8(3), 338-353

- Zimmermann H.J. (1996) Fuzzy Set Theory and its Applications, Kluwer Academic Publishers. 